\title{
Serotonin-Happiness and Satisfaction
}

\author{
Ismail Yousef* \\ BSc of Medical Technology from Misr University of Science and Technology, Jordan \\ *Corresponding author: Ismail Yousef, B.Sc of Medical Technology from MISR University of Science and Technology \\ 2009/2010 Amman, Jordan
}

\begin{tabular}{|c|c|}
\hline ARTICLE INFO & ABSTRACT \\
\hline Received: 凿 January 04, 2021 & $\begin{array}{l}\text { Citation: Ismail Yousef. Serotonin-Happiness and Satisfaction. Biomed J Sci \& Tech Res } \\
\text { 33(3)-2021. BJSTR. MS.ID.005410. }\end{array}$ \\
\hline
\end{tabular}

\section{Mini Review}

We are looking for happiness even though it is close to us, just as you search for your glasses while you are wearing them

\section{The Concept of Happiness}

The perception and concept of happiness differ from one individual to another; however, it is a general feeling that people feel and share; that is, it is available to everyone. People differ in their attitudes and orientations, as some may see happiness in money and others in achievement and success, and the same individual may have a different view of life and influences around him/her according to his/her different phases of time, circumstances and conditions, as there are several hormones called the hormones of happiness such as Melatonin, Oxytocin, Enkephalin, Norepinephrine, Dopamine, Acetylcholine, Endorphins and Serotonin, and the latter hormone is the subject of this article.

\section{What is Serotonin?}

The happiness hormone plays a large and very important role in the process of regulating a person's mood; hence this hormone has been called the hormone of happiness. Besides, the hormone's functions include regulating sexual desire and treating migraine headaches (Arabic: Al-Shaqeqah). The identification of this important hormone present in the human body has contributed to knowing how it is necessary to deal with the depression that afflicts him, as an acute shortage of this hormone was observed in those who suffer from this disease, which contributed and helped in finding a new type of medicine that It works to increase this hormone in the human brain. Hence, it has spread among researchers and people, that the hormone of happiness (serotonin) plays an important, effective, and vital role in a person's sense of psychological reassurance. In some cases, unfortunately, the drugs that raise

the level of serotonin in the body are used without resorting to a specialist, as serotonin syndrome or serotonin poisoning is expected if a person takes two drugs that boost serotonin at the same time and this is what is called the misuse of medicines, so the advice of a specialist should be taken. The level of serotonin (5-Hydroxytryptamine) - (Serotonin) can also be measured in the laboratory to see if there is any deficiency or increase in the body, and again it is necessary to consult a specialist doctor before taking these medications.

\section{Symptoms of Serotonin Deficiency}

Mood disorder, anxiety, depression, weight gain, migraine, premenstrual syndrome, loss of ability to concentrate, severe memory impairment, loss of self-confidence, insomnia and sleep disturbance, and obsessive-compulsive disorder.

\section{How to raise the level of the hormone of happiness?}

One of the most prominent findings is that there is an important, good, and significant relationship between serotonin and the practice of sports activities. It was noticed that the rate of psychological reassurance in addition to calm and comfort increases after a person has finished practicing various sports activities, and for this reason, it has been concluded that sport works significantly and remarkably increases the rate of serotonin, which positively affects the exercise practitioners as they become more comfortable and quieter than before. It has been found that certain types of plants contain a good percentage of serotonin, which reaches 300 microgram/gram in some plants, such as walnuts and other types of plants that include bananas, tomatoes, plums, pineapples, and cocoa. It has been observed that all cocoa products contain serotonin as healthy chocolate. It should also be 
noted that this hormone was discovered for the first time in the digestive system in the human body, where it is found in abundance and regulates bowel function and movements. In conclusion, we have to determine the appropriate foods for our bodies, as people

ISSN: 2574-1241

DOI: 10.26717/BJSTR.2021.33.005410

Ismail Yousef. Biomed J Sci \& Tech Res

(C) $(9)$ This work is licensed under Creative

Submission Link: https://biomedres.us/submit-manuscript.php differ in their nutritional values, but few people know how to have a balanced diet, as health problems abound due to the absence of health awareness and the lack of proper nutrition and exercise culture.

$\begin{array}{ll}\text { BIOMEDICAL } & \text { Assets of Publishing with us } \\ \text { RESEARCHES } & \text { Global archiving of articles } \\ \text { - Immediate, unrestricted online access } & \text { - Rigorous Peer Review Process } \\ & \text { - Authors Retain Copyrights } \\ \end{array}$

